\title{
DESIGN AND DEVELOPMENT OF FLOATING PULSATILE DRUG DELIVERY OF LOSARTAN POTASSIUM
}

\author{
ANIL KUMAR J. SHINDE ${ }^{1}$, NIDHI S. PATIL' ${ }^{1}$, TRUPTI S. JADHAV ${ }^{1}$, HARINATH N. MORE ${ }^{1}$ \\ ${ }^{*}$ Department of Pharmaceutics, Bharati Vidyapeeth College of Pharmacy, Near Chitranagari, Kolhapur (M. S), India \\ Email: ajshinde70@rediffmail.com
}

Received: 03 Apr 2020, Revised and Accepted: 04 Jun 2020

\begin{abstract}
Objective: The objective of the present investigation was to the development of floating pulsatile drug delivery system of Losartan potassium (LP) tablets for obtaining no drug release during floating followed by pulsed, rapid drug release to achieve chronotherapeutic release. In hypertension, the risk of getting heart attacks early in the morning is high and therefore, there was need to develop drug delivery, which will release drugs at morning hours and provide efficacious therapy. LP is a short biological half-life (1.5-2.5h) and readily absorbed from the stomach and upper gastrointestinal tract.
\end{abstract}

Methods: Tablet formulation was prepared by press coating of rapid release core tablets and core tablets were further top coated with a buoyant layer of HPMC K4M and sodium bicarbonate. Various grades of HPMC polymer (E5/E15/E50) were used for the pulsatile coating layer. The developed formulations were characterized for physical characteristics, floating lag time, floating time, release lag time, drug content, swelling index, in vitro dissolution studies, DSC and XRD.

Results: The FTIR and DSC studies predicted that there was no chemical interaction between drug and excipients. The core tablet coated with HPMC E50 showed a high swelling index and release the drug $97.60 \pm 1.2 \%$ at $6 \mathrm{~h}$. Buoyant layer with 80 mg HPMC K4M and 25 mg sodium bicarbonate gave satisfactory floating lag time.

Conclusion: The system showed an excellent lag phase followed by burst release in the distal small intestine, which gives site and time-specific delivery of LP acting as per chronotherapy for treatment of hypertension.

Keywords: Losartan potassium, Floating, Pulsatile, Circadian rhythm, Press coating

(C) 2020 The Authors. Published by Innovare Academic Sciences Pvt Ltd. This is an open access article under the CC BY license (http://creativecommons.org/licenses/by/4.0/] DOI: http://dx.doi.org/10.22159/ijap.2020v12i4.37607. Journal homepage: https://innovareacademics.in/journals/index.php/ijap

\section{INTRODUCTION}

Chronopharmaceutics, the drug delivery based on circadian rhythm, is recently gaining much attention worldwide. Various diseases like asthma, hypertension, and arthritis show circadian variation, which demands time scheduled drug release for effective drug action. To follow this principle, one must have to design the dosage form so that it can be given at a convenient time, e. g. bedtime for hypertension with the drug release in the morning would be a promising chronotherapeutic system. For this, a pulsatile release profile, where the drug is released completely after a defined lag time, is advantageous. A combination of floating and pulsatile principles of drug delivery system would have the advantage that a drug can be released in the distal small intestine after a defined time period of no drug release [1].

The gastroretentive floating pulsatile drug delivery system (GRFPDDS) is useful for those drugs, which have dependent $\mathrm{pH}$ solubility, poor bioavailability in the gastrointestinal tract (GIT) and narrow absorption window. Gastro retentive systems (GRS) can remained in the gastric region for several hours and hence significantly prolong the gastric residence time of drugs. Prolonged gastric retention improves bioavailability, reduces drug waste and improves the solubility of drugs that are less soluble in high $\mathrm{pH}$ environments [2, 3].

Different approaches used for gastroprotection and to enhance the bioavailability of drugs such as floating drug delivery systems (FDDS), bioadhesive or mucoadhesive systems, swelling and expandable systems, high-density systems, raft systems, ion exchange resins, controlled osmotic systems etc. Floating pulsatile dosage forms, which are retained in the stomach for a long time (4$12 \mathrm{~h}$ ) and not affected by variation in gastric $\mathrm{pH}$, local environment or gastric emptying rate. These dosage forms may be either single unit (floating tablets) or multi particulates (beads, pellets, granules, microspheres) with the capability of gastro-retention. These systems are specifically beneficial for drugs, either absorbed from the stomach or requiring local delivery in the stomach [4].

It is well established that many of the body functions display circadian rhythms e. g. in peptic ulcer, the acid secretion is high in the afternoon and night, in case of asthma, precipitation of symptom during the night and early morning is high. Similarly, in cardiovascular disease, blood pressure is at its lowest during the sleep cycle and rises steeply during the early morning awaking period and in arthritis, the pain is more in the early morning. LP is an angiotensin II receptor antagonist used in the treatment of hypertension. The bioavailability of about 33\% and plasma half-life ranging from 1.5 to $2.5 \mathrm{~h}$. The other disorders that follow circadian rhythm are diabetic mellitus, angina pectoris, and rheumatic diseases [5]. Controlled releases that display a pulse release are mainly prepared by polymeric materials and systems that are made up of a reservoir and covered with a barrier. This barrier can be dissolved or eroded after which the drug is released. The release from such formulation can be modified to get a single pulse, double pulse, and multi-pulse release pattern [6].

The aim of the present work was to the development of a pulsatile drug release system of LP for the effective treatment of hypertension. LP is an angiotensin-II receptor antagonist drug which is mainly used to treat high blood pressure and it well absorbed after oral administration.

\section{MATERIALS AND METHODS}

Losartan Potassium was obtained as a gift sample from Macleod's Pharmaceuticals Mumbai, Microcrystalline cellulose, HPMC, sodium bicarbonate were purchased from Loba Chem. Pvt. Ltd. Mumbai, Lactose, Sodium starch glycolate, Cross povidone, Polyvinyl Pyrrolidone, magnesium stearate were purchased from Molychem Mumbai. All other reagents and chemicals used were analytical grade. 


\section{Methods}

\section{Preformulation studies}

The sample of LP was characterized for its physical state, colour and odour. The melting point was determined using a capillary tube method. Solubility study was carried out using different solvents. Fourier transforms infrared (FTIR) spectroscopy studies were used for the evaluation of physicochemical compatibility and interactions among drugs and excipients.

\section{Preparation of rapid release core tablets (RRCT)}

Core tablet was formulated by using various concentrations and different types of diluents and superdisintegrants. The drug, diluent, superdisintegrant and binder were weighed as per formulae given in [table 1]; these were then passed through sieve no.20 transferred to a polybag and blended for $5 \mathrm{~min}$. To the homogeneous blend with magnesium stearate for $2 \mathrm{~min}$. The resulting blend was compressed by using a rotary tablet compression machine to get a tablet of 110 $\mathrm{mg}$ weight with a diameter of $8 \mathrm{~mm}$ [7].

Table 1: Composition of the core tablet of losartan potassium

\begin{tabular}{|c|c|c|c|c|c|c|}
\hline \multirow[t]{2}{*}{ Name of ingredients } & \multicolumn{6}{|c|}{ Batches (mg) } \\
\hline & CT-1 & CT-2 & CT-3 & CT-4 & CT-5 & CT-6 \\
\hline Losartan potassium & 50 & 50 & 50 & 50 & 50 & 50 \\
\hline Microcrystalline cellulose & 46.8 & 29 & 21.8 & 46.8 & 29 & 21.8 \\
\hline Lactose & 10 & 20 & 25 & 10 & 20 & 25 \\
\hline Sodium starch glycolate & 6.6 & 8.8 & 11 & - & - & - \\
\hline Cross povidone & - & - & - & 6.6 & 8.8 & 11 \\
\hline PVP K-30 & 1.1 & 1.1 & 1.1 & 1.1 & 1.1 & 1.1 \\
\hline Magnesium stearate & 1.1 & 1.1 & 1.1 & 1.1 & 1.1 & 1.1 \\
\hline Total weight of tablet & 110 & 110 & 110 & 110 & 110 & 110 \\
\hline
\end{tabular}

\section{Preparation of the pulsatile release tablets (PRTs)}

The optimized pulsatile release tablets were prepared by using different grades of HPMC (E5, E15 and E50) at different concentrations given in [table 2]. Dry coated tablet was prepared by placing $50 \%$ of pulsatile release layer in $10 \mathrm{~mm}$ die and rapid release core tablet (RRCT) layer was placed on it and then remaining quantity of pulsatile release layer was added in the cavity, so as to cover the RRCT and finally compressed using rotary tablet compression machine [8].

Table 2: Composition of PRTs batches

\begin{tabular}{llllll}
\hline Polymer used & Conc. in $\mathbf{~ m g} /$ tablet & & \\
\hline HPMC E5 & 200 & 220 & 240 & 260 & 280 \\
HPMC E15 & 200 & 220 & 240 & 260 & 280 \\
HPMC E50 & 200 & 220 & 240 & 260 & 300 \\
\hline
\end{tabular}

\section{Preparation of floating pulsatile release tablets (FPRTs)}

A $3^{2}$ randomized full factorial design was used to optimize the composition of the buoyant layer. In the design two factors were evaluated, each at three levels and experimental trials were performed at all 9 possible combinations. The concentrations of HPMC K4M $\left(\mathrm{X}_{1}\right)$ and sodium bicarbonate $\left(\mathrm{X}_{2}\right)$ were selected as independent variables. All the nine possible combinations of buoyant powder were filled into the die individually, followed by the addition of optimized PRT and finally, compression was done. The optimized concentrations of HPMCK4M and sodium bicarbonate were incorporated in the floating tablet, which was used as the checkpoint of the regression analysis model. The $3^{2}$ factorial designs for floating pulsatile tablet reported in [table 3]. The independent variables with their actual values were shown in [table 4].

\section{Optimization of formulation using factorial design}

A statistical model incorporating interactive and polynomial term was used to evaluate the responses.

$\mathrm{Y}=\beta 0+\beta 1 \mathrm{X} 1+\beta 2 \mathrm{X} 2+\beta 12 \mathrm{X} 1 \mathrm{X} 2+\beta 11 \mathrm{X} 1 \mathrm{X} 1+\beta 22 \mathrm{X} 2 \mathrm{X} 2 \ldots$. Eq. 1
Where $Y$ is the dependent variable, $\beta_{0}$ is the arithmetic mean response of the nine runs, and $\mathrm{b} 1$ is the estimated coefficient for the factor $\mathrm{x}_{1}$. The main effects $\left(\mathrm{x}_{1}, \mathrm{x}_{2}\right)$ represent the average result of changing one factor at a time from its low to high value. The interaction terms $\left(\mathrm{x}_{1}, \mathrm{x}_{2}\right)$ showed how the response changes when two factors are changed simultaneously. The polynomial terms $\left(\mathrm{x}_{1}, \mathrm{x}_{2}\right)$ are included to investigate nonlinearity. From the data of floating lag time parameters for factorial composition F1 to F9 polynomial equation for the dependent variable has been derived. In this equation, the negative sign indicates a negative correlation and the positive sign indicates a positive correlation to the independent variables $X_{1}$ and $X_{2}[9,10]$.

\section{Evaluation of RRCTs}

Thickness and diameter are important parameters in the evaluation of tablet as it ensures uniformity of tablet size. The thickness of the tablet was determined using a Vernier caliper. Three tablets from formulation were used to measure thickness and diameter and average values were recorded in $\mathrm{mm}$. For each formulation, the hardness of tablets was determined using the Monsanto hardness tester. Force of fracture recorded in $\mathrm{kg} / \mathrm{cm}^{2}$ [11].

Table 3: $3^{2}$ Factorial designs for floating tablet

\begin{tabular}{lll}
\hline $\begin{array}{l}\text { Batches } \\
\text { code }\end{array}$ & Independent variables & Sodium bicarbonate $\left(\mathbf{X}_{2}\right)$ \\
\cline { 2 - 3 } F1 & HPC K4M $\left(\mathbf{X}_{\mathbf{1}}\right)$ & -1 \\
F2 & -1 & 0 \\
F3 & -1 & +1 \\
F4 & -1 & -1 \\
F5 & 0 & 0 \\
F6 & 0 & +1 \\
F7 & 0 & -1 \\
F8 & +1 & 0 \\
F9 & +1 & +1 \\
\hline
\end{tabular}


Table 4: Independent variables with their actual values

\begin{tabular}{llll}
\hline Independent variables & Low (-1) & Medium (0) & High (+1) \\
\hline X1 (HPMC K4M in mg) & 60 & 70 & 80 \\
X2 (Sodium bicarbonate in mg) & 15 & 20 & 25 \\
\hline
\end{tabular}

\section{Weight variation test}

20 tablets were selected randomly, weighed individually and the average weight of tablet was determined. Individual tablet weight was then compared with the average value to find the deviation in weight. The weight variation for each tablet was determined using formula 1 ,

$$
\% \text { weight variation }=\frac{\text { (Individual weight }- \text { average weight) }}{\text { (Average weight) }}
$$$$
\times 100 \ldots 1
$$

Tablet passes the test if not more than two tablet falls outside permitted limit and in no case, any tablet shows variation equal to or greater than twice of permitted limit as per standard.

\section{Drug content}

The content uniformity test was carried out to ensure content of LP in each tablet i.e. to ensure dose uniformity. Ten tablets were weighed and calculate average weight and crushed in to powder in mortar-pestle. Powder triturate equivalent to $50 \mathrm{mg}$ of LP was dissolved in $100 \mathrm{ml} 0.1 \mathrm{~N} \mathrm{HCL}$. Solution was filtered through whatmann filter paper no. 42 and $1 \mathrm{ml}$ of the filtrate was diluted to the $10 \mathrm{ml}$ with $0.1 \mathrm{~N} \mathrm{HCL}$ [12]. Absorbance of the resultant solution was measured using UV-Visible spectrophotometer at $205 \mathrm{~nm}$ wavelength. Content uniformity was calculated using formula 2,

$$
\% \text { Purity }=10 \mathrm{C} \frac{(\mathrm{Au})}{(\mathrm{As})} \ldots .2
$$

Where, C: Concentration, $\mathrm{Au}$ and As: Absorbance's obtained from standard preparation and assay preparation.

\section{In vitro disintegration time}

The disintegration test was carried out using USP in vitro disintegration test apparatus. Tablets were placed in each of the six tubes of the basket, contacting water maintained temperature at 37 ${ }^{\circ} \mathrm{C} \pm 2{ }^{\circ} \mathrm{C}$ as per specified in the individual monograph. The time taken by the tablet for complete disintegration, leaving no tablet residue on wire screen, was recorded.

\section{In vitro dissolution studies}

The release rate of LP from rapid release core tablet was determined using USP dissolution testing apparatus II. The dissolution test was performed using $900 \mathrm{ml}$ of $0.1 \mathrm{~N} \mathrm{HCL}$ at $37 \pm 0.5{ }^{\circ} \mathrm{C}$ and rotation 50 rpm, a sample volume of $5 \mathrm{ml}$ was withdrawn at regular time intervals. The volume withdrawn was replaced by a fresh volume of dissolution medium to maintain sink condition. The filtered samples were analyzed spectrophotometrically at $205 \mathrm{~nm}$ wavelength. Drug content in the dissolution sample was determined [13].

\section{Evaluation of pulsatile release tablets}

Pulsatile release tablets were evaluated for parameters like diameter, thickness, hardness, uniformity of weight, in vitro drug release as per the procedure mentioned for evaluation of core tablet.

\section{Swelling index}

The swelling properties of tablets were determined by placing the tablets in the dissolution test apparatus, in $900 \mathrm{ml}$ of $0.1 \mathrm{~N} \mathrm{HCL}$ at $37 \pm 0.5{ }^{\circ} \mathrm{C}$. The tablets were removed periodically from the dissolution medium, blotted to remove an excess of water and weighed [14]. Swelling characteristics were expressed in terms of percentage of water uptake (WU \%), calculated by formula 3.

$\%$ Water uptake $=\frac{\text { Weight of swollen tablet- Initial weight of tablet }}{\times 100 \ldots .3}$

\section{In vitro dissolution studies}

The release rate of LP from pulsatile release tablets was determined using USP dissolution testing apparatus II (TDT 08L Electrolab
Mumbai, Maharashtra, India). The dissolution study was performed using the same procedure for core tablet $[15,16]$.

\section{Evaluation of floating-pulsatile release tablet (FPRT)}

FPRT was evaluated for parameters like diameter, thickness, hardness, uniformity of weight, in vitro drug release as per the procedure mentioned for evaluation of core tablets.

\section{In vitro buoyancy studies}

The in vitro buoyancy test was conducted by placing the tablet in $900 \mathrm{ml}$ $0.1 \mathrm{~N}$ HCL maintained $\mathrm{pH} 1.2,37 \pm 0.5{ }^{\circ} \mathrm{C}$ temperature and speed of rotation at $50 \mathrm{rpm}$. The time is taken by tablet to float on surface after its introduction in the medium (floating lag time) and entire duration, during tablet remained float on the surface of the medium (total floating time) were recorded by visual observation $[17,18]$.

\section{Fourier transform infrared spectroscopy study (FTIR)}

FTIR absorption spectrum of TA was determined by fourier transform infrared spectrophotometer FTIR (Jasco 4100, Shimadzu, Japan). Briefly, about $2 \mathrm{mg}$ of sample was ground thoroughly with previously dried $\mathrm{KBr}$ at $120{ }^{\circ} \mathrm{C}$ for $30 \mathrm{~min}$; uniformly mixed with drug sample and kept in the sample holder, spectra were recorded over the wavenumber $400-4000 \mathrm{~cm}^{-1}$. Infrared spectrums of pure drug and optimized batches were recorded.

\section{Powder X-ray diffractometry (PXRD)}

PXRD studies were carried out in order to study any change in the crystalline nature of the pure drug and optimized formulation [19, 20]. Study of crystallinity of solids by using Bragg's equation 2,

$$
\mathrm{n} \lambda=2 \mathrm{~d} \sin \theta \ldots . \text { Eq. } 2
$$

Where,

$$
\begin{aligned}
& \mathrm{n}=\text { is an order of diffraction } \\
& \lambda=\text { wavelength of X-rays } \\
& \mathrm{d}=\text { Spacing distance between two planes of crystal } \\
& \theta=\text { Angle of diffraction }
\end{aligned}
$$

\section{Differential scanning calorimetric (DSC) study}

DSC studies provide qualitative and quantitative information about physical and chemical changes of a compound that involve endothermic and exothermic processes, or changes in heat capacity. Thermograms of LP and optimized formulation were obtained using DSC instrument (TA Instruments SDT-2960, USA) equipped with an intra-cooler. Indium standard was used to calibrate the DSC temperature and enthalpy scale. The powder samples of the formulation was kept in the aluminum pan and heated at a constant rate $50{ }^{\circ} \mathrm{C} / \mathrm{min}$, over a temperature range of $100{ }^{\circ} \mathrm{C}$ to $300{ }^{\circ} \mathrm{C}$. Inert atmosphere was maintained by purging nitrogen at the flow rate of $100 \mathrm{ml} / \mathrm{min}[21,22]$.

\section{Stability studies}

The stability studies were carried out according to (ICH) Q1A (R2) guidelines (FDA, 2003). The optimized formulation was subjected to accelerated stability studies at $40 \pm 2{ }^{\circ} \mathrm{C} / 75 \pm 5 \% \mathrm{RH}$ for a period of $2 \mathrm{mo}$ in stability chamber. Tablets were packed in amber-colored wide mouth glass bottle hermetically sealed. The samples were taken out at 30 and $60 \mathrm{~d}$ and evaluated for the physical parameters, \% drug content, in vitro $\%$ drug release study, floating lag time and floating time [23].

\section{RESULTS AND DISCUSSION}

\section{Preformulation studies}

The sample of LP was found to be white to off white crystalline powder having a bitter taste. Melting point of LP was found to be in 
the range of $263-265{ }^{\circ} \mathrm{C}$. LP was found to be soluble in water, methanol, ethanol and acetonitrile. The FTIR spectrum of LP exhibits a characteristic peak at $760 \mathrm{~cm}^{-1}, 1000 \mathrm{~cm}^{-1}, 1462 \mathrm{~cm}^{-1}, 1575 \mathrm{~cm}^{-1}$ and $2995 \mathrm{~cm}^{-1}$ due to chloride moiety, secondary hydroxyl group, aromatic ring, nitrogen moiety and an aliphatic chain respectively.

\section{Evaluation of powder blends}

The powder blend of all the formulations batches (1-6) were subjected for various pre-compressional evaluation parameters such as angle of repose, bulk and tapped density, compressibility index and Hausner's ratio. Results of all the pre-compression parameters performed of the blends for all batches shown in [table 5]. The prepared powder blends were within the limit of all specified values and showed good powder characteristics. Angle of repose was found to be in the range of $23.48^{\circ}$ to $29.78^{\circ}$. The powder blends of all formulations showed good flow property. The bulk density and tapped density of blends were found to be in the range of 0.4647 to $0.4852 \mathrm{~g} / \mathrm{cm}^{3}$ and 0.5076 to $0.55 \mathrm{~g} / \mathrm{cm}^{3}$, respectively. This indicates a good packing capacity of blends. Carr's index was calculated and the results were shown in [table 5]. It was found to be in the range of 5.79 to 14.54 indicates that, the powder blend has required flow property. Values of Carr's index below 15\% usually show good flow characteristics. Hausner's ratio of all formulations was found to be 1.06 to 1.17 indicates the good flow properties of blends.

Table 5: Flow properties of a powder blend

\begin{tabular}{|c|c|c|c|c|c|}
\hline Batch codes & Bulk density $\left(\mathrm{g} / \mathrm{cm}^{3}\right)$ & Tapped density $\left(\mathrm{g} / \mathrm{cm}^{3}\right)$ & Angle of repose $(\theta)$ & Carr's index (\%) & Hausner's ratio \\
\hline 1 & $0.4782 \pm 0.002$ & $0.5076 \pm 0.003$ & $25.07 \pm 0.22$ & $5.79 \pm 0.01$ & $1.06 \pm 0.006$ \\
\hline 2 & $0.4714 \pm 0.003$ & $0.5409 \pm 0.004$ & $25.07 \pm 0.21$ & $12.00 \pm 0.22$ & $1.14 \pm 0.005$ \\
\hline 3 & $0.4852 \pm 0.001$ & $0.5500 \pm 0.003$ & $23.48 \pm 0.32$ & $14.06 \pm 0.18$ & $1.13 \pm 0.006$ \\
\hline 4 & $0.4714 \pm 0.002$ & $0.5500 \pm 0.001$ & $26.82 \pm 0.14$ & $14.54 \pm 0.34$ & $1.17 \pm 0.003$ \\
\hline 5 & $0.4852 \pm 0.004$ & $0.5409 \pm 0.002$ & $29.78 \pm 0.21$ & $10.31 \pm 0.59$ & $1.14 \pm 0.008$ \\
\hline 6 & $0.4647 \pm 0.002$ & $0.5156 \pm 0.002$ & $27.29 \pm 0.22$ & $9.87 \pm 0.02$ & $1.10 \pm 0.008$ \\
\hline
\end{tabular}

*mean $\pm(\mathrm{SD}) \mathrm{n}=3$

\section{Evaluation of RRCTs}

The result indicates that, the mean diameter and thickness of core tablets $(\mathrm{n}=3)$ were found to be within the range of 8.04 to $8.07 \mathrm{~mm}$ and 1.61 to $1.64 \mathrm{~mm}$ respectively. Hardness of core tablets was found to be between 2.81 to $2.9 \mathrm{~kg} / \mathrm{cm}^{2}$. The hardness of all the formulations was almost uniform and the tablets possess good mechanical strength. The percentage weight variations for all tablets were passed test as all the values within range as per the standard limits. The disintegration time of tablets were found to be between
134 to 513s. From the results, it was observed that tablets formulation (CT-6) containing higher concentration of superdisintegrant cross povidone showed rapid disintegration as compared to the formulation (CT-3) containing sodium starch glycolate. In the assay of all the formulation, the tablets of all batches showed $96.39 \pm 0.58$ to $98.96 \pm 0.06 \%$ of drug content, respectively. The results were within the limit (90\% to $110 \%)$ specified in the pharmacopoeia. The results of diameter, thickness, hardness, weight variation test, in vitro disintegration test and drug content were shown in [table 6].

Table 6: Evaluation of RRCT

\begin{tabular}{|c|c|c|c|c|c|c|}
\hline $\begin{array}{l}\text { Batch } \\
\text { codes }\end{array}$ & Diameter (mm) & Thickness (mm) & $\begin{array}{l}\text { Hardness } \\
\left(\mathrm{kg} / \mathrm{cm}^{2}\right)\end{array}$ & $\begin{array}{l}\text { Weight variation } \\
(\%)\end{array}$ & $\begin{array}{l}\text { Disintegration time } \\
\text { (s) }\end{array}$ & Drug content (\%) \\
\hline CT-1 & $8.05 \pm 0.02$ & $1.61 \pm 0.01$ & $2.9 \pm 0.10$ & $109.9 \pm 0.73$ & 513 & $97.57 \pm 0.11$ \\
\hline CT-2 & $8.07 \pm 0.01$ & $1.62 \pm 0.01$ & $2.9 \pm 0.20$ & $109.8 \pm 0.63$ & 460 & $98.73 \pm 0.20$ \\
\hline CT-3 & $8.06 \pm 0.02$ & $1.62 \pm 0.01$ & $2.81 \pm 0.01$ & $110.0 \pm 0.21$ & 406 & $96.39 \pm 0.58$ \\
\hline CT-4 & $8.06 \pm 0.01$ & $1.64 \pm 0.02$ & $2.84 \pm 0.04$ & $109.7 \pm 0.48$ & 253 & $96.45 \pm 0.62$ \\
\hline CT-5 & $8.06 \pm 0.01$ & $1.63 \pm 0.01$ & $3.00 \pm 0.10$ & $109.9 \pm 0.32$ & 190 & $97.64 \pm 0.08$ \\
\hline CT-6 & $8.04 \pm 0.01$ & $1.64 \pm 0.005$ & $2.9 \pm 0.06$ & $110.0 \pm 0.47$ & 134 & $98.96 \pm 0.06$ \\
\hline
\end{tabular}

*mean $\pm(\mathrm{SD}) \mathrm{n}=3$

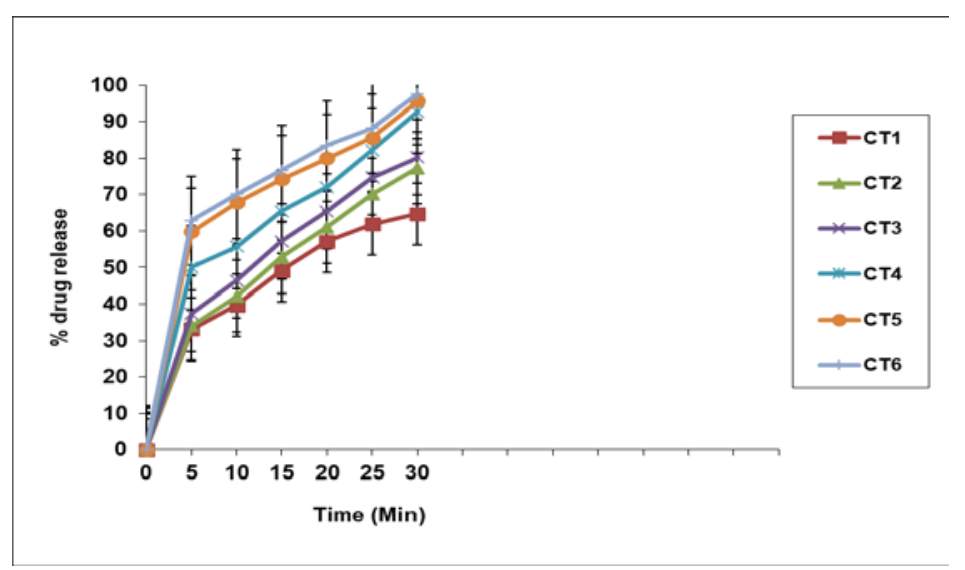

Fig. 1: \% Drug release of RRCTs (mean $\pm S D ; n=3$ )

\section{In vitro dissolution studies}

In vitro drug release studies reveals that, formulations containing cross povidone (CT4-CT6) showed fast dissolution than the sodium starch glycolate. Dissolution of LP RRCTs increases with an increase in the concentration of sodium starch glycolate and cross povidone due to rapid swelling and disintegration. The tablets prepared with cross povidone have maximum drug release as these tablets have less 
disintegration time owing to the formation of larger pores with continuous network in dissolution media and swelling provide enough pressure for faster disintegration, additionally, it also have the capability to swell at least twice of its original volume, when contact with dissolution fluid.

Among six formulations of LP inner core tablets, it was observed that, when cross povidone used in a concentration of $10 \%$ provides rapid disintegration and maximum dissolution rate. Latha $\mathrm{K}$ et al. reported that, Hydroxypropyl methylcellulose (HPMC) forms a firm gel but does not hydrate quickly while MCC is a good disintegrant and acts by a wicking mechanism. Hence, the drug was immediately released from the tablet core after the rupture of the surrounding outer layer containing MCC alone and admixture of HPMC100KM and MCC [7]. In vitro drug release profiles for all the batches of RRCTs of LP are given in [fig. 1].

\section{Evaluation of pulsatile release tablets}

All the tablets formulations were subjected for evaluation of parameters like shape, thickness, diameter, hardness, release lag time, in vitro dissolution studies. The result indicates that, the mean thickness and diameter of PRTs $(n=3)$ were found to be within the range of 2.93 to $4.23 \mathrm{~mm}$ and 10.04 to $10.07 \mathrm{~mm}$ respectively. Hardness of PRTs was found to be between 4.60 to $4.80 \mathrm{~kg} / \mathrm{cm}^{2}$. The hardness of all the formulations was almost uniform and the tablets possess good mechanical strength. From the results, it was revealed that lag time goes on increasing with increasing viscosity grades of HPMC polymer and concentration of polymer. Bajpai et al. reported that coating with carboxymethyl cellulose sodium showed the least lag time because of its high permeation and high water-absorbing character, which leads to quick hydration of core tablet that evolves gas generating internal pressure. Also, carboxymethyl cellulose sodium has a lower extent of cross-linking and gelling character than other three polymers that provided a lesser extent of mechanical strength to its coat [24].

Formulations containing HPMC E5, E15 and E50 showed increasing order of lag time with the respective increase in polymer concentration from 200-300 mg depending on their individual viscosity grades. The results of thickness, diameter, hardness and lag time of PRTs are shown in [table 7]. All the batches of PRTs showed a difference in their dissolution profiles with respect to lag time depending on viscosity grade and concentration of polymer used for the coating of core tablet. Jagdale SC et al. revealed that, as the PRTs of different batches placed in dissolution medium hydrophilic polymeric coat start to erode but it erode up to a limited thickness of tablet as swelling of core tablet because of swelling of disintegrant present in core tablet on contact with dissolution medium result in increased internal pressure and subsequent rupture of polymer coating takes place owing to burst release of the drug. All the batches of PRTs were compared for their physical parameters and drug release profiles with respect to lag time. From the results, it was indicated that PRT coated with $300 \mathrm{mg}$ of the polymer showed maximum release lag time with respect to the ascending order of their viscosity grades (E5<E15<E50). PRTS coated with $300 \mathrm{mg}$ of E5, E15, E50 showed 59.54, 63.74 and $63.37 \%$ drug release after lag time of 165, 270, $390 \mathrm{~min}$, respectively. Even though PRTs coated with HPMC E50 $300 \mathrm{mg}$ showed lag time of $390 \mathrm{~min}$ PRT coated with $280 \mathrm{mg}$ of HPMC E50 selected for treatment of hypertension as it shows the suitable lag time of $360 \mathrm{~min}$ and $97.60 \%$ drug release. Shivhare et al. reported that the ratio of polymer Eudragit increased, there was an increased lag time and decrease in drug release rate. This could cause a decrease in the effective diffusion coefficient of the drug. [25] The results of in vitro drug release of PRTs was shown in [fig. 2,3 and 4].

Table 7: Evaluation of PRTs

\begin{tabular}{|c|c|c|c|c|}
\hline Batch codes & Thickness (mm) & Diameter (mm) & Hardness $\left(\mathrm{Kg} / \mathrm{cm}^{2}\right)$ & Lag time (min) \\
\hline PRT-E5200 & $2.93 \pm 0.002$ & $10.06 \pm 0.01$ & $4.7 \pm 0.10$ & 30 \\
\hline PRT-E5 220 & $3.28 \pm 0.01$ & $10.07 \pm 0.01$ & $4.6 \pm 0.20$ & 60 \\
\hline PRT-E5240 & $3.44 \pm 0.01$ & $10.05 \pm 0.02$ & $4.7 \pm 0.20$ & 90 \\
\hline PRT-E5260 & $3.72 \pm 0.005$ & $10.04 \pm 0.01$ & $4.6 \pm 0.10$ & 135 \\
\hline PRT-E5 280 & $4.06 \pm 0.01$ & $10.06 \pm 0.01$ & $4.7 \pm 0.20$ & 150 \\
\hline PRT-E5300 & $4.23 \pm 0.01$ & $10.06 \pm 0.01$ & $4.6 \pm 0.10$ & 165 \\
\hline PRT-E15 200 & $2.99 \pm 0.02$ & $10.05 \pm 0.02$ & $4.6 \pm 0.23$ & 120 \\
\hline PRT-E15220 & $3.23 \pm 0.01$ & $10.06 \pm 0.02$ & $4.6 \pm 0.10$ & 135 \\
\hline PRT-E15240 & $3.42 \pm 0.11$ & $10.06 \pm 0.01$ & $4.7 \pm 0.20$ & 180 \\
\hline PRT-E15260 & $3.76 \pm 0.15$ & $10.06 \pm 0.011$ & $4.6 \pm 0.10$ & 195 \\
\hline PRT-E15280 & $4.03 \pm 0.02$ & $10.04 \pm 0.01$ & $4.7 \pm 0.10$ & 255 \\
\hline PRT-E15 300 & $4.26 \pm 0.02$ & $10.06 \pm 0.02$ & $4.6 \pm 0.10$ & 270 \\
\hline PRT-E50 200 & $2.97 \pm 0.02$ & $10.07 \pm 0.01$ & $4.7 \pm 0.20$ & 255 \\
\hline PRT-E50 220 & $3.23 \pm 0.01$ & $10.06 \pm 0.01$ & $4.6 \pm 0.10$ & 285 \\
\hline PRT-E50 240 & $3.42 \pm 0.02$ & $10.06 \pm 0.02$ & $4.63 \pm 0.11$ & 315 \\
\hline PRT-E50 260 & $3.74 \pm 0.001$ & $10.05 \pm 0.01$ & $4.7 \pm 0.15$ & 345 \\
\hline PRT-E50 280 & $4.03 \pm 0.01$ & $10.04 \pm 0.01$ & $4.8 \pm 0.20$ & 360 \\
\hline PRT-E50 300 & $4.30 \pm 0.02$ & $10.05 \pm 0.02$ & $4.7 \pm 0.2$ & 390 \\
\hline
\end{tabular}

\footnotetext{
* mean $\pm(\mathrm{SD}) \mathrm{n}=3$
}

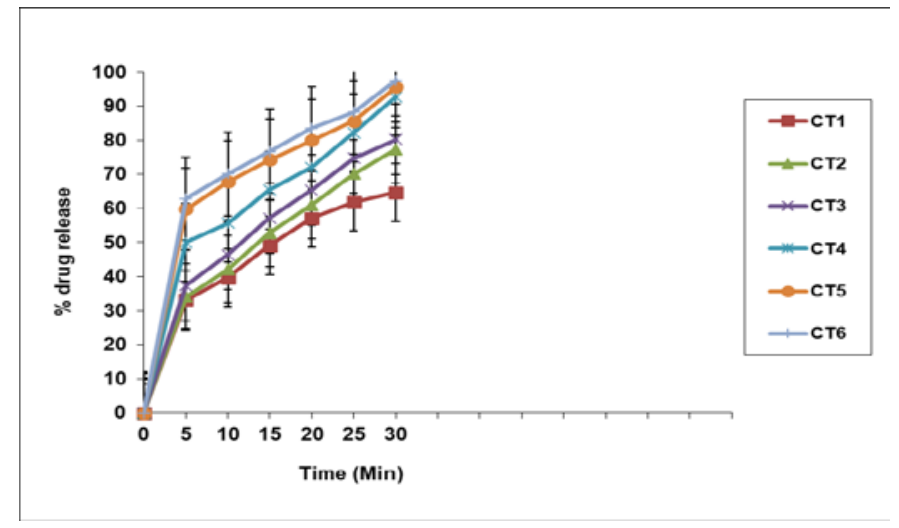

Fig. 2: \% drug release of PRTs coated with HPMC E5 (200-300) (mean \pm SD; n=3) 


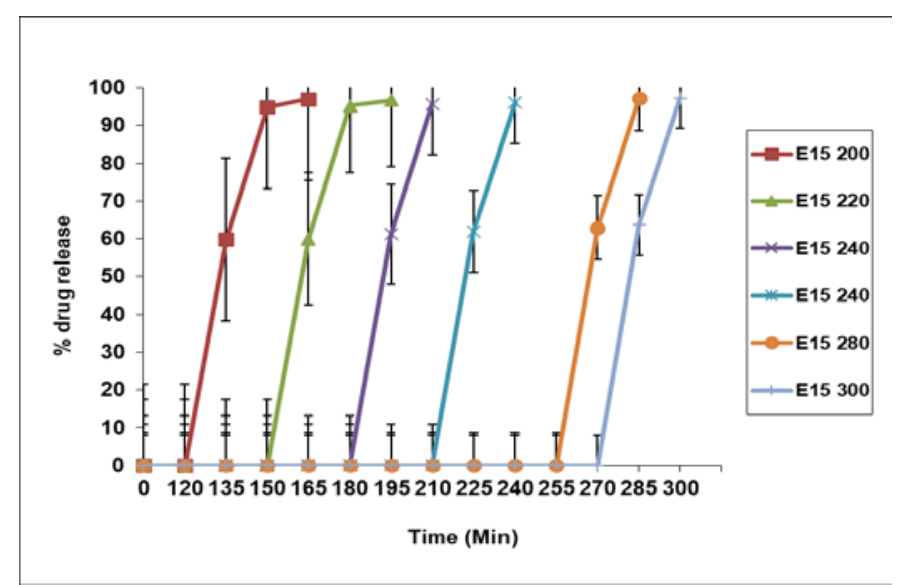

Fig. 3: \% drug release of PRTs coated with HPMC E15 (200-300) (mean \pm SD; n=3)

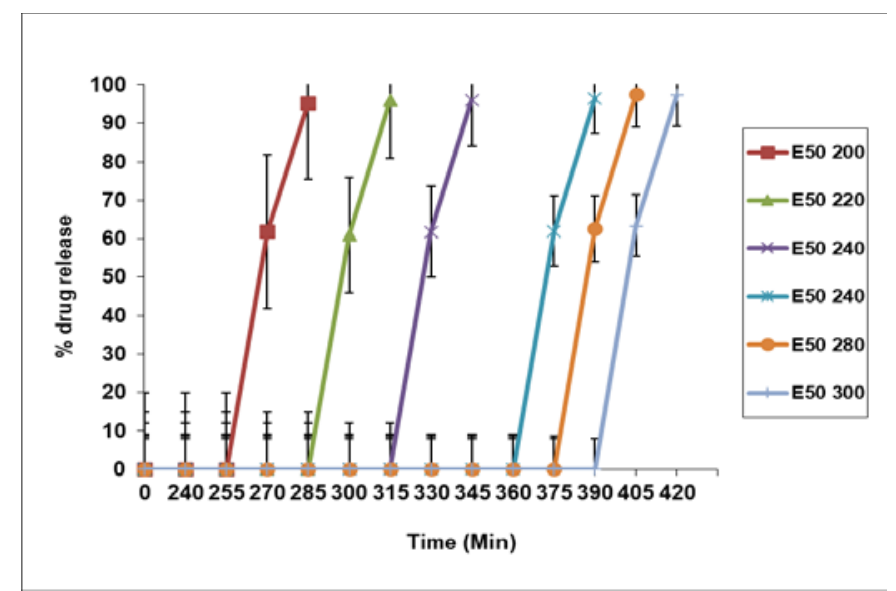

Fig. 4: \% drug release of PRTs coated with HPMC E50 (200-300) (mean \pm SD; $n=3$ )

\section{Swelling index}

The swelling behavior of optimized PRT containing HPMC E50 was compared with other PRTs containing HPMC E5 and HPMC E15 at the same concentration i.e. $280 \mathrm{mg}$. The results indicated that the swelling front erodes faster for PRTs coated with HPMC E5 as compare to PRTs coated with HPMC E15 and E50 due to their marked viscosity properties shown in [fig. 5]. The thickness of the swelled layer of PRT coated with HPMC E50 was higher as compared with PRTs with HPMC E5 and HPMC E15. This was due to the complete penetration of the solvent and high viscosity of the HPMC E50. Raghavendra et al. reported that the ethylcellulose showed highest lag time, which is based upon the hydration of outer barrier layer or water penetration through the outer barrier layer. The formulated bilayered tablets achieved a burst release after 3-4 h lag time [26].

Dhakar VK et al. showed that the direct correlation between swelling and lag time was observed and found that the formulations having maximum swelling indices showed the higher lag time.

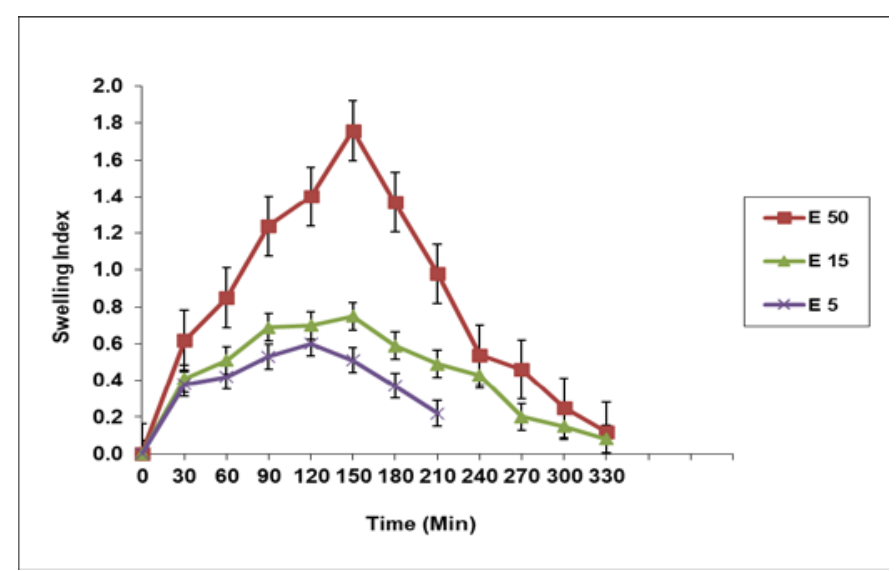

Fig.5: Swelling indices of PRT coated with HPMC E5/E15/E50 (280 mg) (mean \pm SD; n=3) 


\section{Evaluation of floating-pulsatile release tablet (FPRT)}

\section{In vitro Buoyancy studies}

HPMC was a hydrophilic swellable polymer used in controlled release swellable hydrophilic matrices. Reddy et al. reported that, sodium bicarbonate was used as a gas generating agent and this compound generates carbon dioxide on the reaction with acidic aqueous media, which get entrapped into the hydrocolloid gel layer of tablet and due to gas entrapment tablet become buoyant. The equation derived for floating lag time was:

$$
\mathrm{Y}=8.7377-1.3283 \mathrm{X} 1-2.8950 \mathrm{X} 2+3.76 \mathrm{X} 1 \mathrm{X} 2 \ldots . \text { Eq. } 3
$$

The $\beta_{0}=8.73$, which is the arithmetic mean of all nine batches. The negative coefficient of $X_{1}$ indicates that as the concentration of $X_{1}$ (HPMC K4M) increases; there is a decrease in the floating lag time of tablets. The negative coefficient of $\mathrm{X}_{2}$ indicates that as the concentration of $\mathrm{X}_{2}$ (sodium bicarbonate) increases, the floating lag time of tablet was decreased. $3^{2}$ full factorial designs with observed responses shown in [table 8]. The surface response curve shown in [fig. 6].

\section{Fourier transform infrared spectroscopy studies}

The FTIR spectrum of formulation F9 shows a broad peak at $3753.23 \mathrm{~cm}^{-1}$, indicating the presence of the primary alcoholic $\mathrm{OH}$ group. A peak is shown at $1542 \mathrm{~cm}^{-1}$ and $775.19 \mathrm{~cm}^{-1}$, depicting nitrogen and chloride moiety. One sharp peak of aryl chloride was observed at $1117 \mathrm{~cm}^{-1}$. In comparison with the pure drug, the absorption peak of the spectra for LP in FPDDS form optimized formulation batch F9 showed no significant shift of characteristic peaks suggesting that there is no interaction between drug and excipients. IR spectra of LP, physical mixture and optimized formulation batch F9 as shown in [fig. 7-9].

Table 8: Coded level as per $3^{2}$ full factorial designs with observed responses

\begin{tabular}{lllll}
\hline Batch codes & X1 & X2 & Floating lag time (min) & Floating time (in h) \\
\hline F1 & -1 & -1 & $19: 21$ & $>12$ \\
F2 & -1 & 0 & $10: 04$ & $>12$ \\
F3 & -1 & +1 & $8: 56$ & $>12$ \\
F4 & 0 & -1 & $11: 37$ & $>12$ \\
F5 & 0 & 0 & $9: 15$ & $>12$ \\
F6 & 0 & +1 & $7: 23$ & $>12$ \\
F7 & +1 & 0 & $5: 25$ & $>12$ \\
F8 & +1 & +1 & $5: 16$ & $>12$ \\
F9 & +1 & +1 & & $>12$ \\
\hline
\end{tabular}

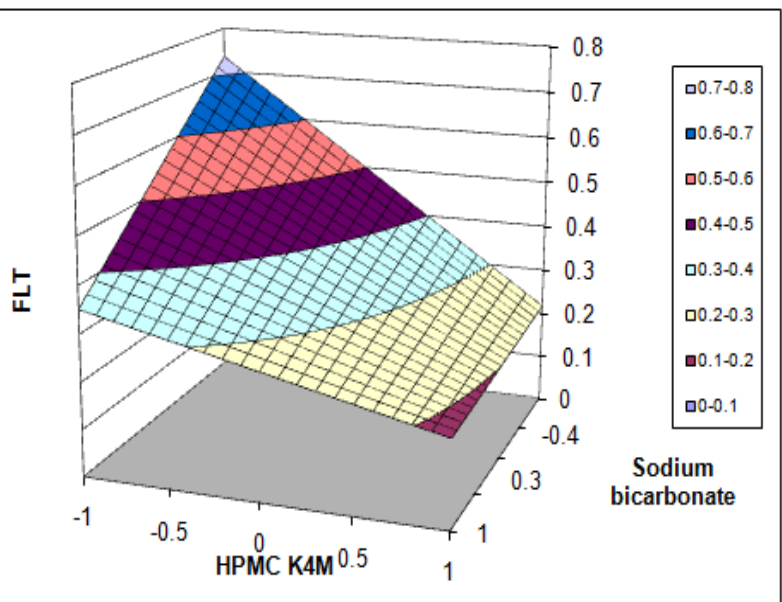

Fig. 6: Response surface plot showing the effect of factorial variables on floating lag time and floating time

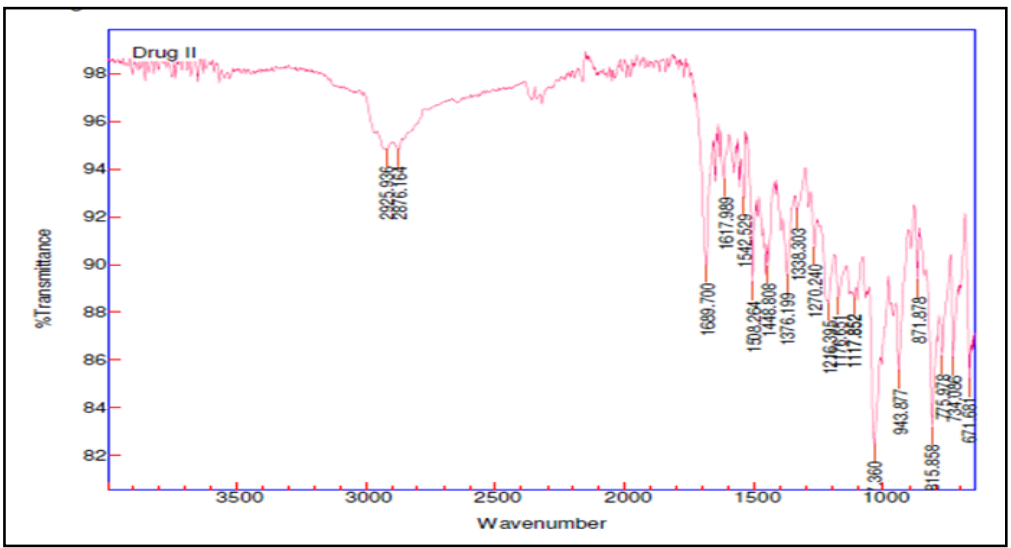

Fig. 7: IR spectra of losartan potassium 


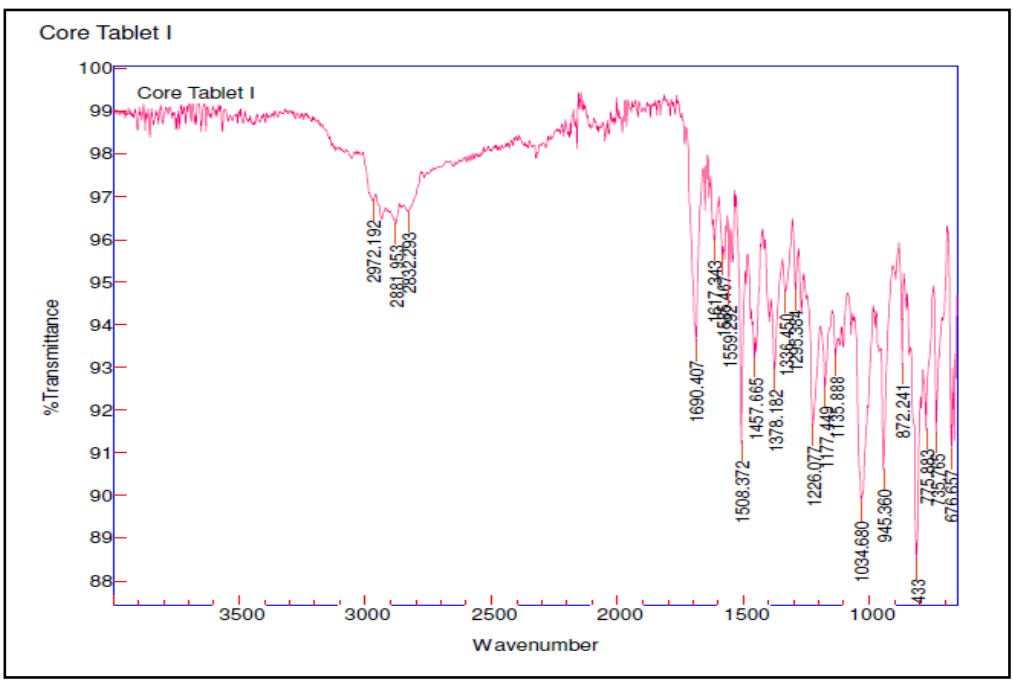

Fig. 8: IR spectra of the physical mixture of batch CT-6

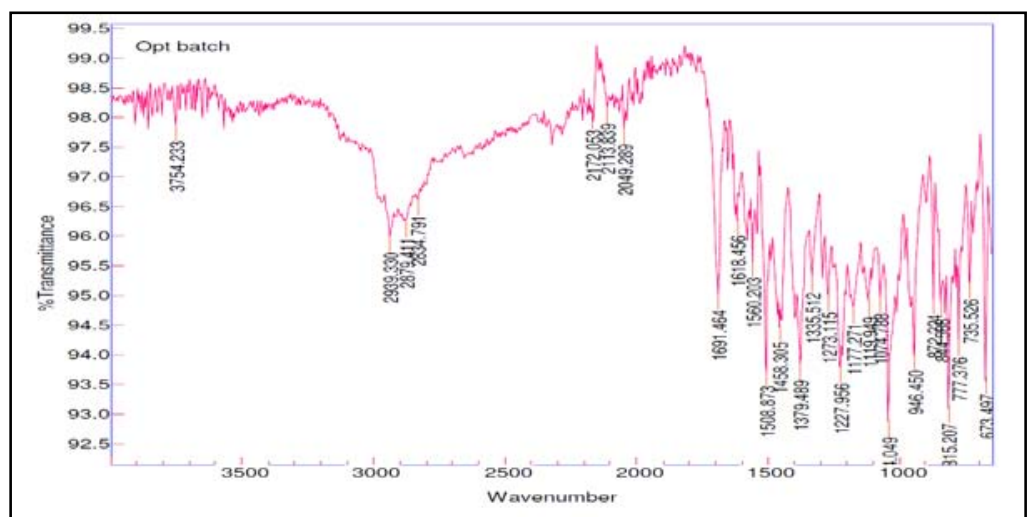

Fig. 9: IR spectra of optimized batch F9

\section{Powder X-ray diffractometry studies}

PX-RD spectra indicated that the sharp peaks were seen in the PXRD spectra of the pure drug indicates crystalline nature of drug while optimized formulation (F9) has shown the peaks with reduced intensities denoting reduced crystallinity of drug. The overlay of PX$\mathrm{RD}$ pattern of pure drug and optimized formulation (F9) was shown in [fig. 10].

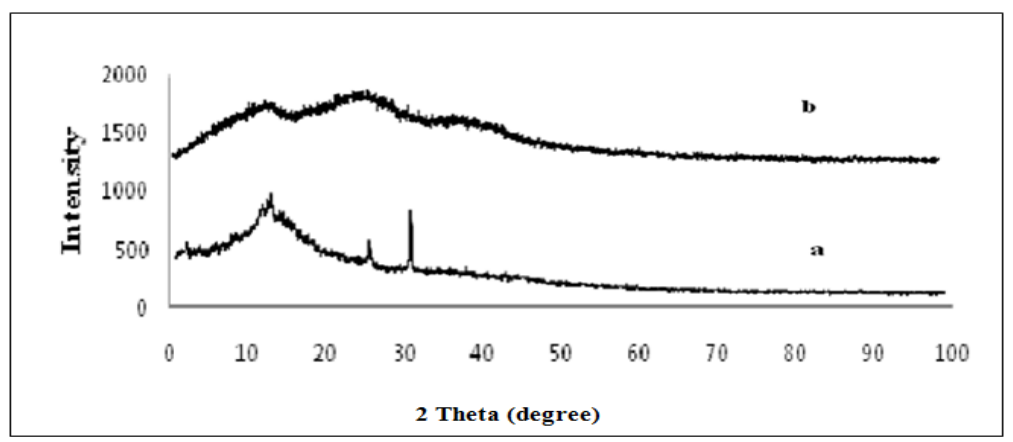

Fig. 10: Overlay PX-RD spectra of pure drug (a) and optimized batch F9 (b)

\section{Differential scanning calorimetry studies}

DSC studies were conducted for the study of physical state of the drug in the formulation. In the thermogram of pure drug, sharp endotherm was obtained at near about $260.91^{\circ} \mathrm{C}$, which shows the melting point of the drug. The LP has shown an endothermic peak at $260.91{ }^{\circ} \mathrm{C}$. The peak was shifted in the case of DSC of the LP optimized batch formulation. The DSC of the tablet triturate of FPRT of LP showed an endothermic peak at $199.49^{\circ} \mathrm{C}$. The results reveals that there was a reduction in crystallinity in the polymer matrix and no incompatibility between drug and other excipients.

The thermograms of LP and optimized batch (F9) shown in [fig. 11 and 12]. 


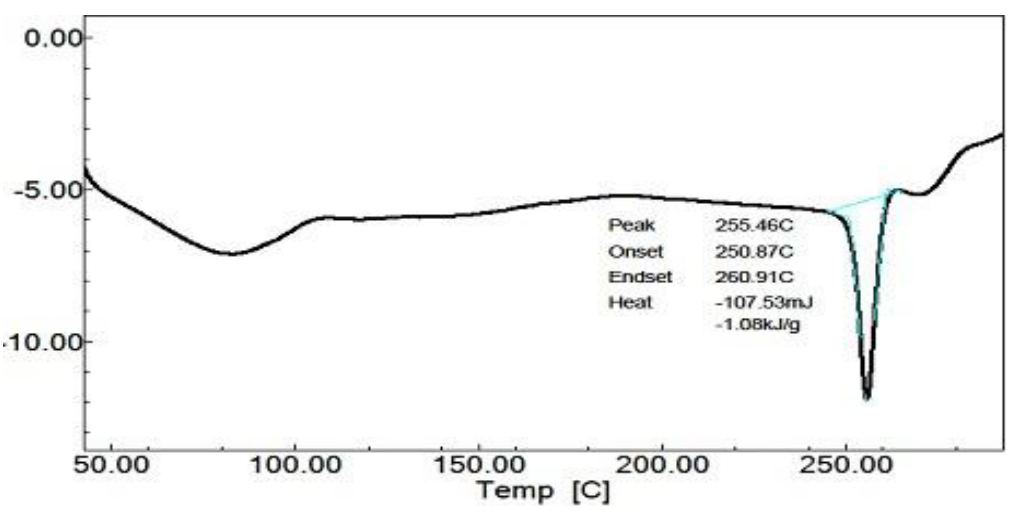

Fig. 11: DSC thermogram of losartan potassium

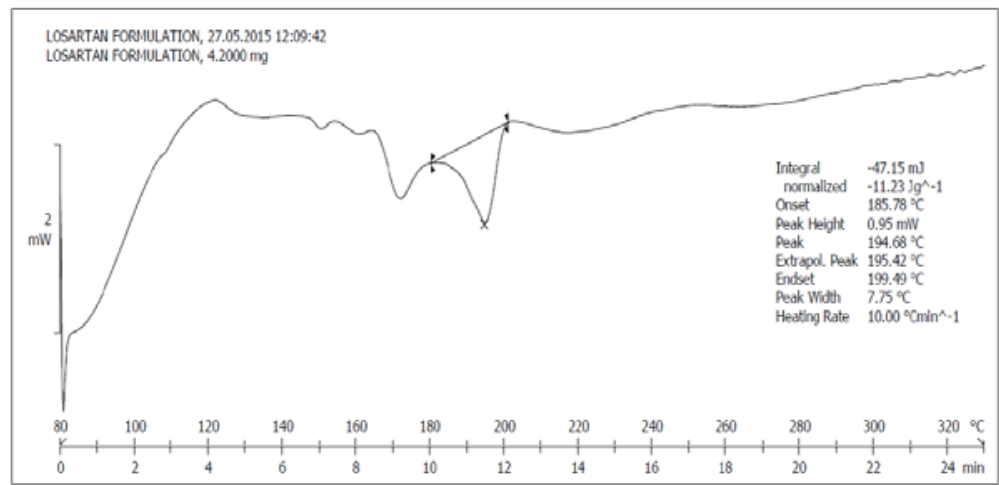

Fig. 12: DSC thermogram optimized batch F9

\section{Stability studies}

Short term stability study was performed for formulation CT-6 at $40 \pm 2.0{ }^{\circ} \mathrm{C}$ and $\mathrm{RH} 75 \% \pm 5 \%$ for two months. The samples were analyzed for diameter, thickness, weight variation, hardness, disintegration time, percent drug content and in vitro drug release studies. The results of all parameters indicated that no significant difference in parameters observed before and after stability studies shows in [table 9]. Short term stability studies of FPRTs were performed of the optimized formulation F9, indicated that there was no significant difference in physical parameters, floating lag time and floating time shown in [table 10].

Table 9: Evaluation parameters of optimized core tablet (CT-6)

\begin{tabular}{lll}
\hline Parameters & Before & After \\
\hline Diameter (mm) & $8.04 \pm 0.01$ & $8.03 \pm 0.01$ \\
Thickness (mm) & $1.64 \pm 0.005$ & $1.64 \pm 0.01$ \\
Weight variation (\%) & $110.0 \pm 0.47$ & $109.9 \pm 0.6$ \\
Hardness ( $\left.\mathrm{kg} / \mathrm{cm}^{2}\right)$ & $2.90 \pm 0.06$ & $3.00 \pm 0.02$ \\
Disintegration time $(\mathrm{s})$ & $134 \pm 0.02$ & $135 \pm 0.02$ \\
Drug content (\%) & $98.96 \pm 0.06$ & $98.35 \pm 0.01$ \\
In vitro $\%$ drug release & $97.60 \pm 0.20$ & $97.00 \pm 0.42$ \\
\hline
\end{tabular}

${ }^{*}$ mean $\pm(S D) n=3$

Table10: Evaluation of FPRTs

\begin{tabular}{lll}
\hline Parameters & Before & After \\
\hline Diameter $(\mathrm{mm})$ & $10.04 \pm 0.002$ & $10.06 \pm 0.004$ \\
Thickness $(\mathrm{mm})$ & $4.8 \pm 0.002$ & $4.7 \pm 0.004$ \\
Floating lag time (min) & $5.06 \pm 0.02$ & $6.32 \pm 0.01$ \\
Floating time (h) & $>12$ & $>12$ \\
\hline
\end{tabular}

*mean $\pm(\mathrm{SD}) \mathrm{n}=3$

\section{CONCLUSION}

The FPDDS was developed successfully using press coating technique. The present investigation revealed that the coating of core tablet with $280 \mathrm{mg}$ of HPMC E50 and top coating of PRT with floating layer containing $80 \mathrm{mg} \mathrm{HPMC} \mathrm{K} 4 \mathrm{M}$ and $25 \mathrm{mg}$ sodium bicarbonate provided desired lag time required for chronotherapy of hypertension. The optimized formulation showed $6 \mathrm{~h}$ of pulsatile 
release lag time, 5 min floating lag time and greater than $12 \mathrm{~h}$ of floating time. In vitro drug release study showed $97.60 \%$ drug release in $0.1 \mathrm{~N}$ HCL within $30 \mathrm{~min}$, indicating burst release. Optimized formulation (F9) showed good stability at accelerated stability conditions. From the experimental findings it can be concluded that floating pulsatile tablets of Losartan potassium can give efficient therapy by reducing dose and dosing frequency and provide chronotherapy for an effective management of morning surge of hypertension. Finally, it may be concluded that floating pulsatile drug delivery system offers a valuable dosage form treatment of hypertension.

\section{ACKNOWLEDGMENT}

Anilkumar J. Shinde and co-authors are thankful to Macleod's Pharmaceuticals Mumbai India for the gift sample of Losartan hydrochloride.

\section{FUNDING}

Nil

\section{AUTHORS CONTRIBUTIONS}

The author designed and performed the experiment analyzed data and prepared the manuscript. All authors played an equal role in completing this research work.

\section{CONFLICT OF INTERESTS}

The authors declared no conflict of interest.

\section{REFERENCES}

1. Dalvadi H, Patel JK. Chronopharmaceutics, pulsatile drug delivery system as current trend. Asian J Pharma Sci 2010;5:204-30.

2. Kakade TB, Shelar DB, Tikole SS, Bamane GS, Ubale AT. Floating pulsatile drug delivery system: an overview. Int Res J Invent Pharma Sci 2014;2:151-62.

3. Parmar RD, Parikh RK, Vidyasagar G, Patel DV. Pulsatile drug delivery system: an overview. Int J Pharma Sci Nanotech 2009;2:605-14

4. Rajput M, Sharma R, Kumar S, Jamil F, Sharma S. Pulsatile drug delivery system: a review. Int J Res Pharm Bio Sci 2012;3:118-24.

5. Survase S, Kumar N. Pulsatile drug delivery. Curr Scenario Crips 2007;8:27-33.

6. Sahitya G, Krishnamoorthy B, Muthukumaran M. Importance of preformulation studies in designing formulations for sustained release dosage forms. Int J Pharm Tech 2013;4:2311-31.

7. Latha K, Uhumwangho MU, Sunil SA, Srikanth MV, Ramanmurthy KV. In vitro evaluation of oral timed-release tablet of losartan potassium using natural gum and it's solid characterization. Int J Pharm Pharma Sci 2012;4:89-95.

8. Subbarao J, Venkateswara Rao P, Vidyadhara S, Venkateswara Rao B, Sasidhar R. L. C, UV spectrophotometric validation for identification and determination of losartan potassium in tablets. Int J Pharm Tech 2012;4:4137-43.
9. Dhakar VK, Chaurasia B, Kar A. Development and evaluation of floating pulsatile multiparticulate drug delivery system using aceclofenac as a model drug. Int J Pharm Life Sci 2012;3:1787-96.

10. Avulapati S, Roy AK, Shashidhar KR. Formulation and evaluation of taste-masked and fast disintegrating Losartan potassium tablets. Int J Drug Dev Res 2011;3:45-51.

11. Rathnanand $M$, Pannala S. Formulation and in vitro evaluation of floating pulsatile tablets of nizatidine for chronotherapy of ulcers. J Pharm Res 2011;4:1338-90.

12. Reddy BV, Navaneetha K, Ramana Reddy KV. Process development and optimization for moisture activated dry granulation method for losartan potassium tablets. Int J Pharm Pharma Sci 2011;6:312-7.

13. Sokar MS, Hanafy AS, Kamel AH. Pulsatile core-in-cup valsartan tablet formulations: in vitro evaluation. Asian J Pharma Sci 2013;8:234-43.

14. Krogel I, Bodmeier R. Floating or pulsatile drug delivery systems based on coated effervescent cores. Int J Pharma 1999;187:175-84.

15. Zou H, Jiang X, Kong L, Gao S. Design and evaluation of a dry coated drug delivery system with the floating-pulsatile release. J Pharma Sci 2008;97:263-73.

16. Naik JB, Zine SP. Development of single unit floating pulsatile site-specific drug delivery system for the chronotherapeutic release of aceclofenac. Int J Appl Bio Pharma Tech 2011;2:339-48

17. Patel S, Modasia MK, Patel VM, Patel AK. Design and development of floating pulsatile drug delivery system using meloxicam. Int J Pharma Res Bio-Sci 2012;1:215-35.

18. Naik CS, Rao Basaveswara. Design and formulation development of fast-dissolving tablets of ibuprofen using novel natural superdisintegrant. Asian J Pharma Clin Res 2019;12:34-41.

19. Jagdale SC, Suryawanshi VM, Pandya SV, Kuchekar BS, Chabukswar AR. Development of press-coated, floatingpulsatile drug delivery of lisinopril. Sci Pharm 2014;82:423-40.

20. Badve SS, Sher P, Korde A, Pawar AP. Development of hollow/porous calcium pectinate beads for floating-pulsatile drug delivery. Eur J Pharma Biopharma 2007;65:85-93.

21. Shaji J, Patole V. Novel floating pulsatile approach for chronotherapeutic release of Indomethacin. J Pharma Sci 2007;6:37-41.

22. Ganesh NS, Deecaraman. Chromodulated drug delivery system of lornoxicam using natural polymers. J Pharma Res 2011;4:825-28.

23. Patel KT, Mahajan AN, Shah DA. Studies in formulation development of chronotherapeutics dosage of model drug. Der Pharm Lett 2011;3:227-40.

24. Bajpai M, Singh DC, Bhattacharya A. Design and in vitro evaluation of compression-coated pulsatile release tablets of losartan potassium. Indian J Pharm Sci 2012;74:101-6.

25. Shivhare UD. Formulation and evaluation of pulsatile drug delivery system of Losartan potassium by using factorial design. Int J Pharma Sci Nanotech 2013;5:1895-901.

26. Raghavendra K, Marina K. An investigation on formulation and evaluation of specialized chronotherapeutical drug delivery system of losartan and hydrochlorothiazide for the treatment of hypertension. Sudi J Med Pharm Sci 2017;3:310-7. 